\title{
Patterns of bacterial diversity in the marine planktonic particulate matter continuum
}

\author{
Mireia Mestre, Encarna Borrull, M Montserrat Sala and Josep M Gasol \\ Department of Marine Biology and Oceanography, Institut de Ciències del Mar, CSIC. Barcelona, Catalunya, \\ Spain
}

\begin{abstract}
Depending on their relationship with the pelagic particulate matter, planktonic prokaryotes have traditionally been classified into two types of communities: free-living (FL) or attached (ATT) to particles, and are generally separated using only one pore-size filter in a differential filtration. Nonetheless, particulate matter in the oceans appears in a continuum of sizes. Here we separated this continuum into six discrete size-fractions, from 0.2 to $200 \mu \mathrm{m}$, and described the prokaryotes associated to each of them. Each size-fraction presented different bacterial communities, with a range of $23-42 \%$ of unique (OTUs) in each size-fraction, supporting the idea that they contained distinct types of particles. An increase in richness was observed from the smallest to the largest sizefractions, suggesting that increasingly larger particles contributed new niches. Our results show that a multiple size-fractionation provides a more exhaustive description of the bacterial diversity and community structure than the use of only one filter. In addition, and based on our results, we propose an alternative to the dichotomy of FL or ATT lifestyles, in which we differentiate the taxonomic groups with preference for the smaller fractions, those that do not show preferences for small or large fractions, and those that preferentially appear in larger fractions.
\end{abstract}

The ISME Journal (2017) 11, 999-1010; doi:10.1038/ismej.2016.166; published online 3 January 2017

\section{Introduction}

Particulate matter in the oceans appears in a high variety of types, in a continuum of sizes from truly dissolved to visible macroaggregates (Azam et al., 1993; Azam, 1998; Simon et al., 2002; Verdugo et al., 2004). This continuum is dynamic and patchy (Long and Azam, 2001) and can present hot spots of microbial activity (Alldredge et al., 1986; Azam et al., 1993; Seymour et al., 2004). Depending on their relation with the particulate matter present in the environment, planktonic microorganisms have traditionally been classified into two types of communities: free-living (FL) or attached (ATT). It is well known that ATT pelagic prokaryotes can develop dense communities of cells (Simon et al., 2002), and present specialized metabolisms characterized by high rates of extracellular enzyme activity (Karner and Herndl, 1992; Smith et al., 1992), prokaryotic production (Kirchman and Mitchell, 1982) and respiration (Grossart et al., 2007). In contrast, FL microorganisms tend to have smaller genomes (Smith et al., 2013) adapted to low substrate

Correspondence: M Mestre or JM Gasol, Department of Marine Biology and Oceanography, Institut de Ciències del Mar, CSIC, Passeig Maritim de la Barceloneta, 37-49, Barcelona E08003, Spain.

E-mail: mireia@icm.csic.es or pepgasol@icm.csic.es

Received 6 June 2016; revised 4 October 2016; accepted 17 October 2016; published online 3 January 2017 concentrations, with high expression of membrane transporter genes (Satinsky et al., 2014), and tend to exhibit motility (Mitchell et al., 1995; Fenchel, 2001; Grossart et al., 2001).

To analyze both communities, microbial ecologists use differential filtration, so that the first filter retains the ATT communities while the FL prokaryotes go through that filter and are collected by a second (typically $0.2 \mu \mathrm{m}$ ) filter. There is a wide range of filters used to distinguish between FL and ATT fractions: $0.8 \mu \mathrm{m}$ (Schapira et al., 2012), $1.6 \mu \mathrm{m}$ (Ganesh et al., 2014), $3.0 \mu \mathrm{m}$ (Eloe et al., 2011), $5.0 \mu \mathrm{m}$ (Lapoussiere et al., 2011), or even $30 \mu \mathrm{m}$ (Fuchsman et al., 2011) pore sizes. But most of these studies have used only one size to separate ATT from FL and have thus missed the possibility of detecting, if they exist, diverse ATT communities associated to distinct sizes. A few studies have focused on two size-fractions (for example, 0.8 and $10 \mu \mathrm{m}$ (Dang and Lovell, 2002), 1.0 and $60 \mu \mathrm{m}$ (Kellogg and Deming, 2009), 0.8 and $3.0 \mu \mathrm{m}$ (Smith et al., 2013 and Wilkins et al., 2013) and 3.0 and $8.0 \mu \mathrm{m}$ (Milici et al., 2016)), yet no one has systematically used a set of different sized filters to size fractionate bacterioplankton samples. The lack of consensus on the pore-size used to separate both types of communities makes a comparison among studies very difficult or even impossible. The choice of the filter may bias the results as distinct filters might retain distinct particles with distinct bacterial communities. 
Moreover, the use of various size-fractions might reveal a more comprehensive view of bacterioplankton complexity by contemplating a wider variety of habitats where planktonic bacteria develop.

Considering that the biogeochemical role of prokaryotes in the microbial food web depends strongly on the size, quantity and quality of the suspended particles (Malfatti and Azam, 2009; Grossart, 2010a), current studies should perhaps deviate from the traditional dichotomy of ATT vs FL communities and take into account the variety of sizes and complexity of organic and inorganic structures that can be found in the water column and that might serve as prokaryotic niches. To test this idea, we analyzed marine bacterial communities in different size-fractions, ranging from the purely FL to particles of $200 \mu \mathrm{m}$, in an oligotrophic coastal station of the Mediterranean Sea, and all along a year. The microbes were collected by serial filtration on six filters of decreasing pore sizes, to test whether the composition of the bacterial community differs among the size-fractions and to explore whether a multiple size-fractionation of the samples provides a more complete description of the whole bacterial community than the use of only one filter to separate FL from ATT communities. The null hypothesis would be that microbial community composition shows no relationship with the pore-size of the filter and, by extension, to the sizes of the particles.

\section{Materials and methods}

\section{Study area, sampling and basic parameters}

Samples were collected monthly from June 2012 to June 2013 from the Blanes Bay Microbial Observatory (BBMO, www.icm.csic.es/bio/projects/icmicro bis/bbmo/) a coastal station (20 m depth) placed at 0.5 miles offshore $\left(41^{\circ} 40^{\prime} \mathrm{N}, 002^{\circ} 48^{\prime} \mathrm{E}\right)$ in the $\mathrm{NW}$ Mediterranean Sea which has regularly been sampled for microbial ecology studies during the last decades (Gasol et al., 2012). Surface water (0.5 m depth) was taken and pre-filtered through a $200 \mu \mathrm{m}$ mesh net and transported to the laboratory in darkness. For DNA analysis, a total of $10 \mathrm{l}$ were filtered sequentially through $20,10,5,3,0.8$ and $0.2 \mu \mathrm{m}$ pore-size polycarbonate filters $(20 \mu \mathrm{m}$ poresize filter from GE Water and Process Technologies (Trevose, PA, USA) and the rest of the filters from Millipore (Billerica, MA, USA)) of $47 \mathrm{~mm}$ diameter, using a peristaltic pump at very low speed and pressure. To prevent clogging we changed the filters when the flow slowed down (usually the 0.2 and $0.8 \mu \mathrm{m}$ pore-size filters were replaced at least once per filtration). All the filters of the same pore-size were pooled as one sample. The filters were stored inmediatelly at $-80^{\circ} \mathrm{C}$ until extraction. The sizefractions were defined as: $0.2-0.8 ; 0.8-3.0 ; 3.0-5.0$; $5.0-10 ; 10-20$; and $20-200 \mu \mathrm{m}$, and in order to simplify the nomenclature, they will also be referred by the lowest size (that is, ' 0.8 fraction' indicates from 0.8 to $3 \mu \mathrm{m}$ ) along the manuscript. A description of the measurement of environmental parameters and the abundance of prokaryotes on those filter sizes can be found in Supplementary Methods 1.

DNA extraction, sequencing and sequences processing The DNA was extracted as described in (Massana et al., 1997). Hypervariable V1-V3 $16 \mathrm{~S}$ tags were PCR amplified and 454 GS FLX+ pyrosequenced with primers $28 \mathrm{~F} / 519 \mathrm{R}$ by Research and Testing Laboratory (Lubbock, TX, USA; http://www.research andtesting.com/). A total of 495897 amplicon fragments were produced. Reads from 150 to $600 \mathrm{bp}$ were quality checked (Phred quality average $>25$ ) by using a $50 \mathrm{bp}$ sliding window in QIIME (Caporaso et al., 2010). Pyrosequencing errors were reduced with Denoiser in QIIME. Reads were clustered into Operational Taxonomic Units (OTUs) with a 97\% similarity threshold with UCLUST in QIIME. Chimeras were detected with ChimeraSlayer (Haas et al., 2011) and SILVA108 as a reference database, in MOTHUR (Schloss et al., 2009). Taxonomy assignment was done using SILVA Incremental Aligner (SINA v1.2.11). Unwanted OTUs (eukaryotes, chloroplast, mitochondria or OTUs with less than five sequences in total) were removed. The months with at least one size-fraction that could not be amplified were discarded. A total of 48 samples where selected, representing 8 months: September, October, November and December of 2012 and January, March, April and June of 2013. The samples were randomly subsampled to the lowest number of reads present in the data set. A summary of sequence information can be found in Supplementary Table 1.

\section{Data analysis}

Statistical analyses and graphs were done in $\mathrm{R}$ (www.r-project.org) and JMP software (www.jmp. com). The OTU table was square-root transformed and a Bray-Curtis distance matrix was generated. The environmental database was normalized and an Euclidean distance matrix was generated. Nonmetric multidimensional scaling analysis was used to visualize the distances between communities. A PERMANOVA (Adonis test, vegan-Package) was performed to discern statistically significant differences due to the factors size-fraction and month. Bray-Curtis distances were calculated between samples of September 2012 and the respective sizefractions of the following months. The diversity of each size-fraction was calculated using the Shannon Index (H') and the True Alpha, Beta and Gamma Diversity (Tuomisto, 2010) with R package Simba. Similarities among size-fractions were explored with the average clustering method (Unweighted Pair Group Method with Arithmetic Mean: UPGMA), and a SIMPROF analysis was performed to detect the significant clusters (at $P<0.05$ ). Rank-abundance curves for each size-fraction were plotted in log-log 
scales. Indicator OTUs (Dufrene and Legendre, 1997) of a given size-fraction were obtained using the INDVAL analysis ( $\mathrm{R}$ package lavdsv, INDVAL values $>0.3$ and $P<0.05$ ). Niche Breadth (Bj; Levins, 1968) of each OTU was calculated and OTUs with $\mathrm{Bj}<3$ were considered specialists, OTUs with $\mathrm{Bj}=[3-4]$ were considered Intermediate and OTUS with $\mathrm{Bj}>4$ were considered generalists. OTUs with relative abundance $>1 \%$ were considered abundant, those at $1-0.1 \%$ were considered intermediate, and those $<0.01 \%$ were considered rare.

The OTUs were grouped at phylum, class and genera level. The high-rank taxonomic groups which represented $>1 \%$ of the total abundance in at least one size-fraction, were selected for further analyses. The rest were classified as 'other bacteria'. With these criteria, a total of 17 taxonomic groups were selected. To assess differences in the relative abundances of individual taxonomic groups among size-fractions, analysis of variance $(P<0.05)$ and Tukey's post-hoc tests were conducted. Relative abundances of the taxonomic groups were drawn in a heatmap and were clustered hierarchically by the UPGMA method.

\section{Results}

The environmental parameters of the eight sampled dates presented elevated variability (the CVs were on average 57\%; Supplementary Table 2). The nonmetric multidimensional scaling plot (Figure 1) indicated that the samples clustered by month and by size-fraction. A PERMANOVA test (Supplementary Table 3) confirmed that differences between 'size-fractions' were significant $(P<0.001)$ and differences between 'months' were also significant $(P<0.001)$. Bray-Curtis distances between distinct months (Supplementary Figure 1) showed annual periodicity, being the community composition of nearby months more similar than those of distant months. The communities of smaller size-fractions remained rather constant over the year, compared with the communities of the larger size-fractions. Most ( $94 \%$ on average) bacteria were in the $>0.2 \mu \mathrm{m}$ filter, while $4.9 \%$ were in the $0.8 \mu \mathrm{m}$ filter, and $<0.5 \%$ were present in the remaining filters (Supplementary Figure 2).

Bacterial diversity increased with increasing sizefraction at each month as indicated by the Shannon Index and species richness (Figures 2a and b). The 20-200 $\mu \mathrm{m}$ size-fraction presented the most diverse community, whereas the $0.2-0.8 \mu \mathrm{m}$ size-fraction had the lowest diversity. The average $\alpha$-diversity (diversity within a size-fraction) was 179.8, the global $\beta$ (rate of community differentiation among size-fractions) was 3.3 and the global $\gamma$ (total diversity within the six size-fractions) was 595.6 (Supplementary Table 4). The accumulated number of species in the range of the size-fractions (species discovery curve or species-accumulation curve) presented a logarithmic form, which reached a 'plateau' and was close to saturation (Figure 3). A clustering dendrogram (Figure 4) revealed that every fraction shared OTUs preferentially with the closest size-fractions. Lower levels of dissimilarity were found in the larger size-fractions (that is, they were more similar among them). A SIMPROF analysis to detect significant clustering $(P<0.05)$ separated primarily the smallest fraction $(0.2-0.8 \mu \mathrm{m})$ from the rest of fractions, and secondly the $0.8-3.0 \mu \mathrm{m}$ size-fraction from the larger fractions. The larger fractions clustered by pairs: $3.0-5.0 \mu \mathrm{m}$ with $5.0-10 \mu \mathrm{m}$ and $10-20 \mu \mathrm{m}$ with $20-200 \mu \mathrm{m}$. The rank-abundance curves (Figure 5) indicated that each size-fraction presented a strong dominance generated by a few OTUs, yet the size-fractions with higher dominance (that is, the smaller fractions) presented less diversity, as can be observed by the steeper slope in this representation.

On an average ( \pm s.d.), the percentage of unique OTUs in each size-fraction ranged from
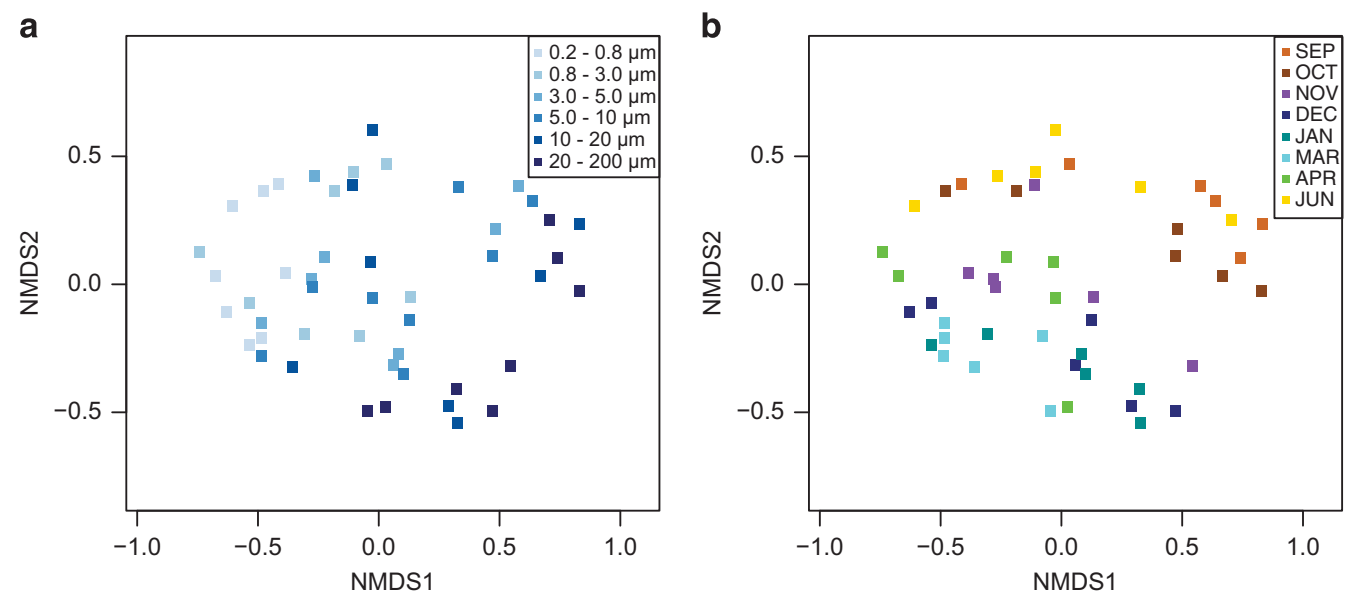

Figure 1 Non-metric multidimensional scaling (nMDS) representing the distance between samples by size-fraction (a) and month (b). The nMDS was created with a Bray-Curtis distance matrix derived from the OTU table. 

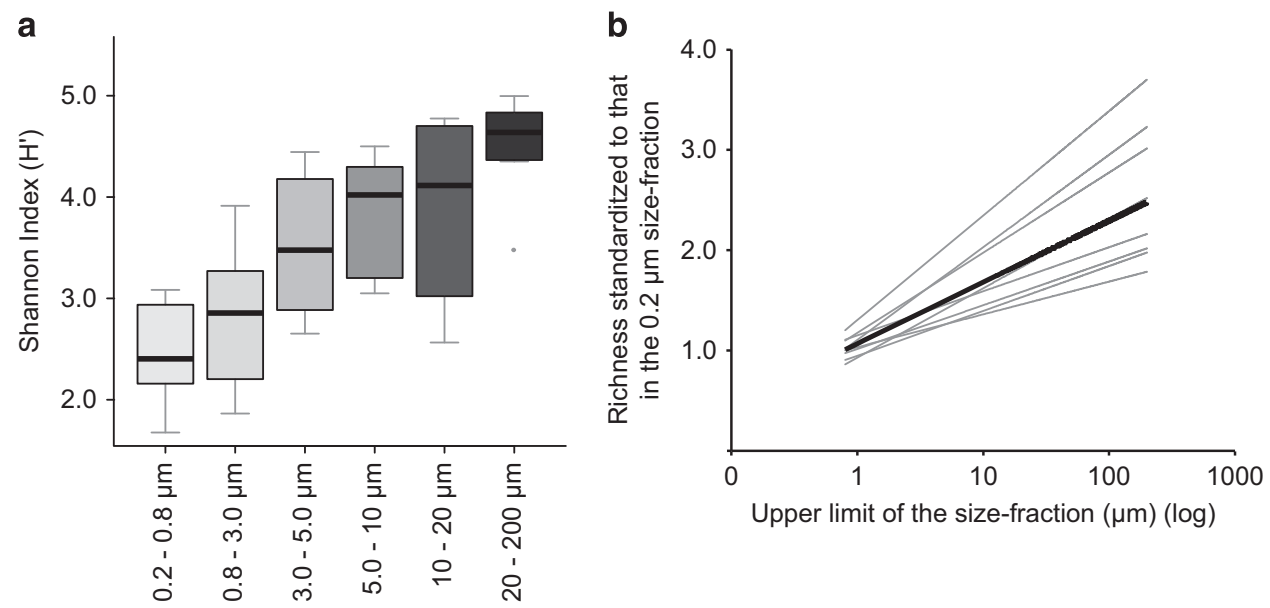

Figure 2 (a) Box-plot of the Shannon diversity Indices for each size-fraction. Upper and lower lines correspond to the first and third quartile of the distribution of values. The median values are shown with horizontal black wide lines. Outliers are displayed as dots. (b) Richness standardized to that of $0.2 \mu \mathrm{m}$ for each size-fraction and for each month. The lines correspond to the log-linear regressions between the size of the fraction and richness. The thick line is the log-linear regression of the average values.

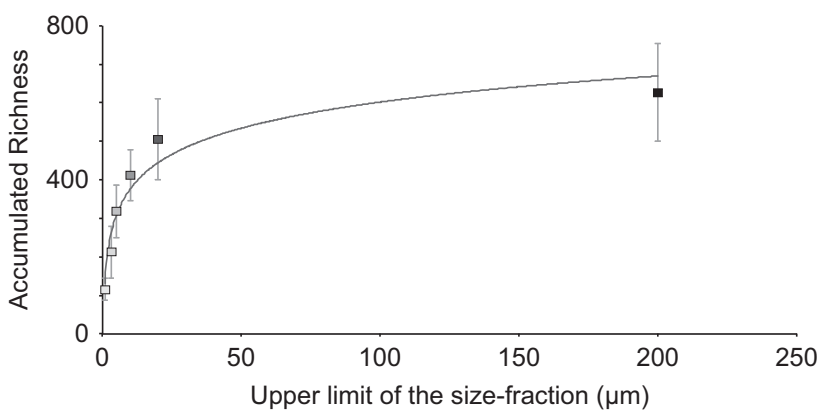

Figure 3 Species-accumulation curve, representing the number of OTUs (species) accumulated from the smallest to the largest sizefraction. The curve was constructed with the median values of the 8 months, with its s.d. The equation of the curve: $y=97.7 \ln (x)+152$. $\mathrm{R}^{2}=0.95$.

$23 \pm 4.5 \%(3.0-5.0 \mu \mathrm{m})$ to $42.6 \pm 7.9 \%(20-200 \mu \mathrm{m})$ (Supplementary Table 5), and the percentage of shared OTUs by all size-fractions (that is, ubiquitous, with global co-ocurrence) accounted for $3.3 \pm 1.1 \%$ of the total OTUs (Supplementary Table 6). The percentage of shared OTUs between two sizefractions (co-ocurrence between two size-fractions) ranged from $23.7 \pm 6.8$ to $44.7 \pm 6.7 \%$ (Supplementary Table 7), where every fraction shared species preferentially with the closest size-fractions and the highest percentages were found in the intermediate fractions. A total of 49 Indicator OTUs were identified (INDVAL $>0.3, P<0.05$ ) (Supplementary Table 8). The size-fractions with higher numbers of indicator OTUs were the size-fraction $0.2-0.8 \mu \mathrm{m}$ and the $20-200 \mu \mathrm{m} \quad(24$ and 18 , respectively).

When separating the values of Niche Breadth (Bj) into three ranks of abundances (Supplementary Table 9), specialists were predominantly 'rare' $(<0.01 \%$ abundant $)$ and generalist OTUs were predominantly 'abundant' ( $>1 \%$ abundant). The number of specialist OTUs increased with the size of the fraction, while the number of generalist OTUs decreased with the size of the fraction (Figure 6a). The relative abundances of the specialists decreased from 0.2 to $3.0 \mu \mathrm{m}$ and increased from 3.0 to $20 \mu \mathrm{m}$. The contrary was observed for the relative abundances of the generalist organisms (Figure 6b).

Analysis of variance tests showed that 16 of the 17 selected (that is, relatively dominant) taxonomic groups presented statistically significant differences in relative abundances among size-fractions (Supplementary Table 10). Considering the differential presence of each group in the six particle-sizes (Figure 7) and the samples clustering (Figure 8), a total of four categories could be differentiated. The first category (A) encompassed the taxonomic groups that were enriched in the smallest size-fractions: for example, SAR11 and SAR116. The second category (B) comprised the taxonomic groups that were enriched in the smaller size-fractions, but depleted or absent in the smallest size-fraction $(0.2-0.8 \mu \mathrm{m})$ : for example, Synechococcus sp. The third category 


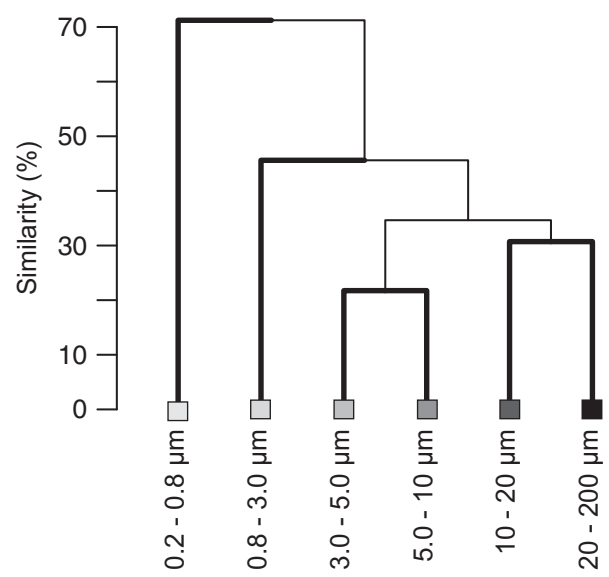

b

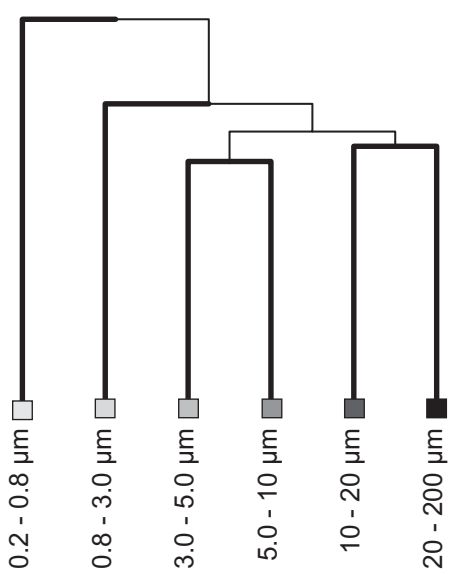

Figure 4 Clustering dendrograms of the six size-fractions calculated by average clustering criteria (Unweighted Pair Group Method with Arithmetic Mean, UPGMA). Data used is the average of the distance between two size-fractions of the 8 months, with: (a) relative abundance data; and (b) presence-absence (binary) data. Thick lines indicate significant differences (determined by SIMPROF).

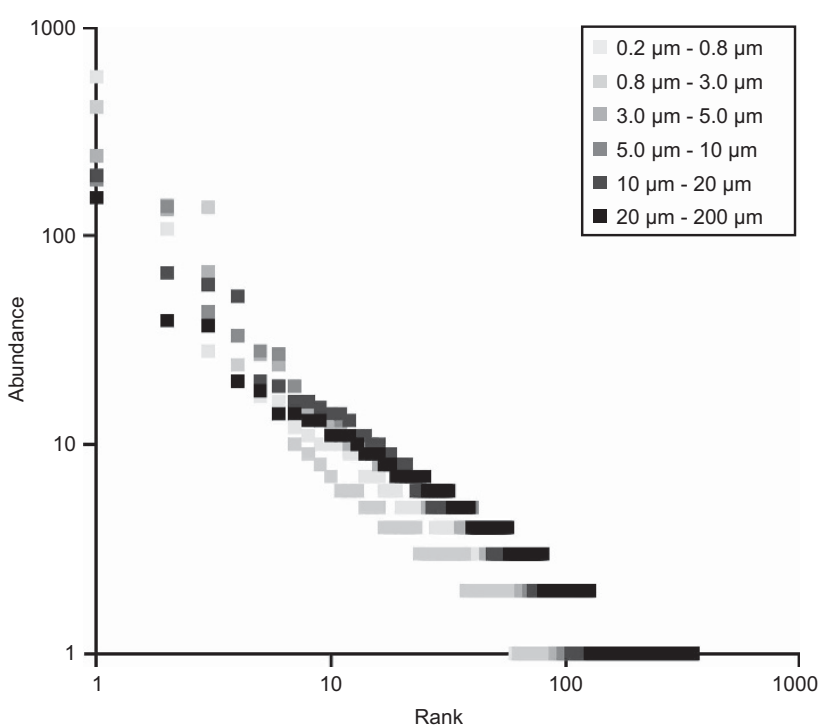

Figure 5 Rank-abundance curve for the six size-fractions, represented as a log-log plot. The data represent the average values in each of the 8 months.

(C) included the taxonomic groups that did not present enrichment when increasing or decreasing the size-fraction: for example, Deferribacterales, Oceanospirillales, Actinobacteria. The fourth category (D) was composed of taxonomic groups that were enriched in the lager size-fractions: for example, Rhodobacterales, Cytophagia, Alteromonadales, Verrucomicrobia, Vibrionales, Spingobacteriia, Firmicutes, Planctomycetes, Deltaproteobacteria, Flavobacteria and Rhizobiales.

\section{Discussion}

We describe here the diversity of a coastal bacterioplankton community by using a serial filtration system designed to separate the continuum of sizes of the plankton particulate matter into six discrete sizefractions. Our approach is unique because most studies that have analyzed the diversity of FL vs PA communities have done so by using only one or two filter sizes. In addition, we have inspected a broader range of sizes (from 0.2 to $200 \mu \mathrm{m}$ ). Our choice of the filters was based on the most common filters used to separate the various types of communities found in the literature. Many studies have considered as 'FL fraction' all bacteria that passed through $0.8 \mu \mathrm{m}$ filters, yet in quite some studies the size limit chosen was the $3 \mu \mathrm{m}$ as they intended to recover also the very large bacteria. Others considered that the 'ATT fraction' starts at $5.0 \mu \mathrm{m}$ or even at larger sizes. Here, by characterizing the different bacterial communities present in various size-fractions we obtained information on the size dependence of bacterial community structure, a protocol that reveals a more comprehensive view of the pelagic microorganisms in the plankton. The data comprised here covers almost a year-round data set of the Blanes Bay Microbial Obsevatory including high variability in terms of environmental parameters and bacterial community composition (Figure 1, Supplementary Table 2 and 3, Supplementary Figure 1). Despite this high seasonal variability, we describe patterns of bacterial diversity in the size-fractions that were conserved all along the year. We consider that these patterns are strong, conserved with time, and have the potential to be present also in other aquatic systems. From our data we cannot state that this is a general trend across all aquatic ecosystems yet the patterns derived from the analysis of the six sizefractions in our samples is a null hypothesis to be tested in further studies.

A common question addressed in FL vs ATT bacterial studies is to determine which size-fraction contains more diversity. Previous studies performed 

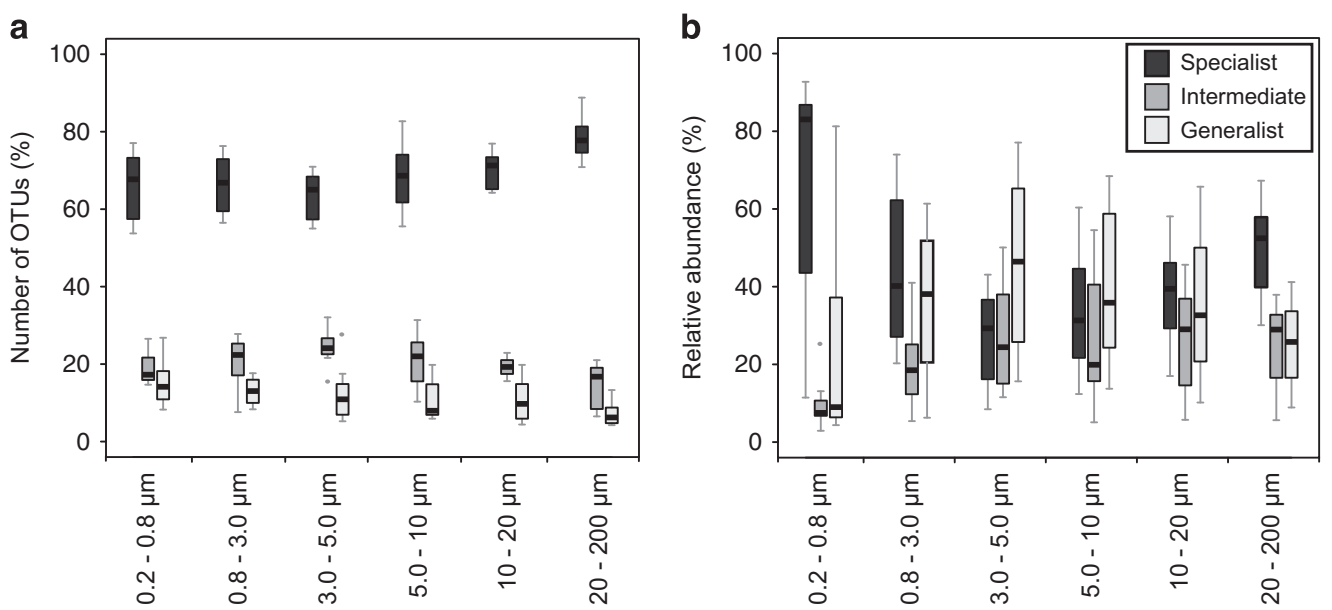

Figure 6 Specialist, Intermediate and Generalist OTUs (see Material and Methods for definition) in each size-fraction, represented as: (a) number of OTUs; and (b) their relative abundances. The boxplots were constructed with the upper and lower lines corresponding to the first and third quartile of the distribution. The median values are shown with horizontal black wide lines. Outliers are displayed as dots.

in marine areas close to our sampling site have shown contradictory trends: some found more diversity in the FL fraction (Acinas et al., 1999; Ghiglione et al., 2007), whereas other studies found more diversity in the ATT fraction (Crespo et al., 2013). The same occurs in other marine ecosystems: some authors found that FL communities were richer than ATT communities (Hollibaugh et al., 2000; Moeseneder et al., 2001), whereas other authors found the opposite (Zhang et al., 2007; Eloe et al., 2011; Fuchsman et al., 2011; Ortega-Retuerta et al., 2013; Bižic-Ionescu et al., 2015). Still, others found a gradient, with more diversity in the smallest sizefractions (Kellogg and Deming, 2009). A recent study across a latitudinal gradient in the Atlantic found that in some of the sampled stations the small sizefraction was the richest, whereas in other stations the larger size-fraction presented more diversity (Milici et al., 2016). This highly contrasting conclusions could be produced by the different filters used in the various studies or because of the distinct kinds of particles present in each environment. Here, we covered a broader range of sizes and we analyzed more size-fractions. Our data reflect that the diversity is variable in each size-fraction depending on the season, but there is always an increase of diversity from the smallest to the largest size-fractions. Diversity tripled from the commonly considered FL sample (that is, $0.2-0.8 \mu \mathrm{m}$ ) to the largest sizefraction ( $>200 \mu \mathrm{m}$, Figure 2a and b). Moreover, the larger fractions presented lower levels of dominance compared with the smallest fractions, being dominance and diversity inversely proportional in all size-fractions (Figure 5). Our results indicate that there is a high decrease in the abundance of bacteria per unit of volume in the larger fractions (on average $94 \%$ bacteria were in the $0.2 \mu \mathrm{m}$ fraction, $4.9 \%$ bacteria were in the $0.8 \mu \mathrm{m}$ fraction, and less than $0.5 \%$ were present in the remaining size-fractions in these samples, Supplementary Figure 2). Thus, according to our results, the larger the size-fraction, the more bacterial diversity is contained, even though there are fewer bacteria per unit of volume.

We also observed that the \% of unique OTUs in each filter ranged from 23 to $42 \%$ (Supplementary Table 5), indicating that the six size-fractions analyzed contained different environments (that is, types of particles) that created distinct niches and that contributed to the global differentiation of bacterial communities. Interestingly, we observed more specialist organisms (in number of OTUs and in relative abundance) with increasing size-fraction, which could be understood as an increase in the number of distinct niches with the increase of the size-fraction. The existence of these niches could be assigned to the development in larger particles of chemical gradients including low levels of oxygen or even anoxia (Alldredge and Cohen, 1987), and where biogeochemical processes such as denitrification (Karl et al., 1984) or methanogenesis could be present. In fact, in the large size-fractions we detected Tenacibaculum sp. that are known to carry out nitrate reduction (Suzuki et al., 2001) and thus develop in microaerophilic conditions; Blastopirellula sp. that are known to perform nitrate reduction under anoxic conditions (Anammox; Schlesner et al., 2004); facultative anaerobes such as Vibrio sp. (Baumann et al., 1980), and strict anaerobes such as Propionigenium sp. (Schink and Pfennig, 1982). In particular, these organisms were identified as sizefraction indicator species according to our analysis (Supplementary Table 8). In addition, the sizefractionation scheme would also separate the phytoplankton and zooplankton present in the nano- and microsized fractions, and thus the distinct bacterial communities that they harbor. The phytoplankton community in Blanes Bay is generally dominated throughout the year by Prymnesiophyceae $(\sim 5 \mu \mathrm{m})$ and episodically by Bacillariophyta $(2-200 \mu \mathrm{m})$ (Gutiérrez-Rodríguez et al., 2011), and the 

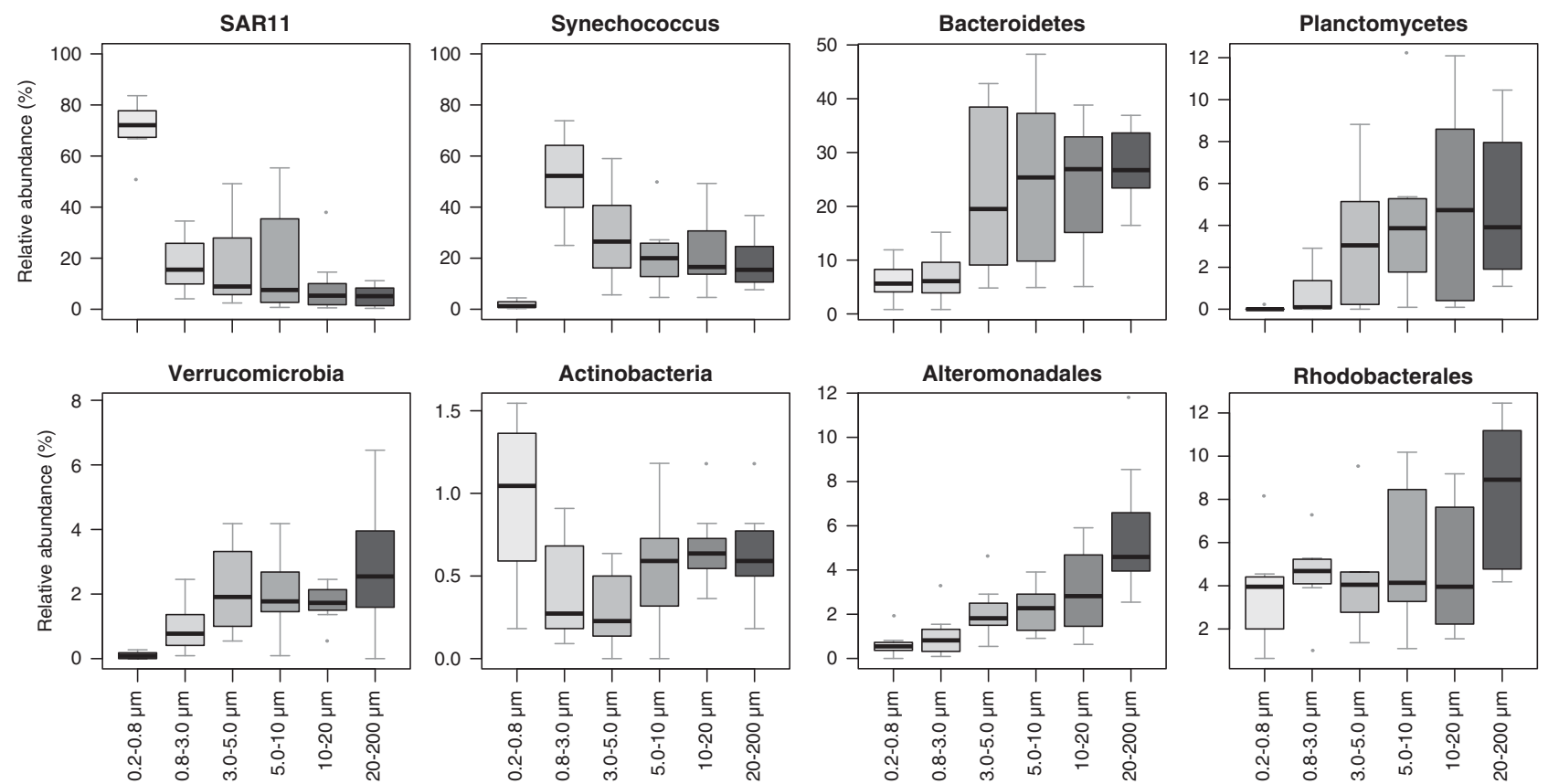

Figure 7 Selected taxonomic groups and their distribution (in relative abundance) among the six size-fractions: SAR11, Synechococcus sp., Bacteroidetes, Planctomycetes, Verrucomicrobia, Actinobacteria, Alteromonadales, Rhodobacterales. Boxplots were constructed with the upper and lower lines corresponding to the first and third quartile of the distribution. The median values are shown with horizontal black wide lines. Outliers are displayed as dots.

zooplankton community is dominated by nauplii and copepodites, in the 53-200 $\mu \mathrm{m}$ and 20-200 $\mu \mathrm{m}$ size-fractions respectively (Calbet et al., 2001; Almeda et al., 2011). Several studies have shown that certain bacterial OTUs can be associated to certain phytoplankton taxa (for example, Pinhassi et al., 2004; Sala et al., 2005; Sison-Mangus et al., 2016) and, to a lesser extent, also to zooplankton (Grossart et al., 2010b; Bickel et al., 2014). Thus, the higher diversity and the higher percentage of unique OTUs in the larger size-fractions can also presumabily be related, at least in part, to the specific bacterial communities attached to phytoplakton and $<200 \mu \mathrm{m}$ zooplankton.

There is not a strict separation between ATT and FL, and it likely exists a dynamic exchange between these categories (Grossart, 2010a). The presence of commonly considered FL groups in large particles can be explained if they have the potential to also live attached to particles, they search refuge from predation in particles, they form filaments or cellular aggregates, they are parasites or symbionts of protists or phytoplankton, or they are hitchhiking on protists or zooplankton (Grossart et al., 2010b). By contrast, the presence of commonly considered ATT bacteria in small size-fractions could be explained if they can also live as FL or if they are individual cells dispersing from an aggregate. It may be argued that filtration, the most common method to separate FL and ATT lifestyles, may cause clogging and disaggregation. With clogging, FL would be retained in larger size-fractions. And by disaggregation, ATT bacteria could pass through the filter to smaller size- fractions. We minimized both processes by prefiltering all the sample through $200 \mu \mathrm{m}$, filtering a reduced water volume (10l in total), using very low vacuum pressure, and changing the filters when the flow slowed down. Our data indicate that several taxonomic groups can be found in more sizefractions than one. Moreover, we can associate various preferences to some of the high-rank taxonomic groups: some were enriched when increasing the size-fraction, some were enriched when decreasing the size-fraction, some did not enrich when increasing or decreasing the size-fraction, and some were enriched when decreasing the size-fraction but were depleted or absent in the smallest size one (Figures 7 and 8). We believe this is a new perspective that might allow a better understanding of the natural history of the different bacterial taxonomic groups in relation with the particulate matter present in the environment.

Various remarkable organisms could be assigned to each of the categories cited above. 'SAR11' were present all along the continuum of size-fractions but were enriched in the smallest size-fraction (Figure 8: category 'a'). They were $\sim 70 \%$ of the community in the $0.2 \mu \mathrm{m}$ fraction, and $5-15 \%$ in the remaining size-fractions. Their elevated presence in the smallest size-fraction is understandable since isolates of this group are known to have a very reduced size, and genomic studies of the first cultured member of this clade (Pelagibacter ubique) indicate adaptation to a mostly FL lifestyle (Giovannoni et al., 2005). Yet, some SAR11 have also been observed in larger sizefractions, and have been considered as ATT ecotypes 


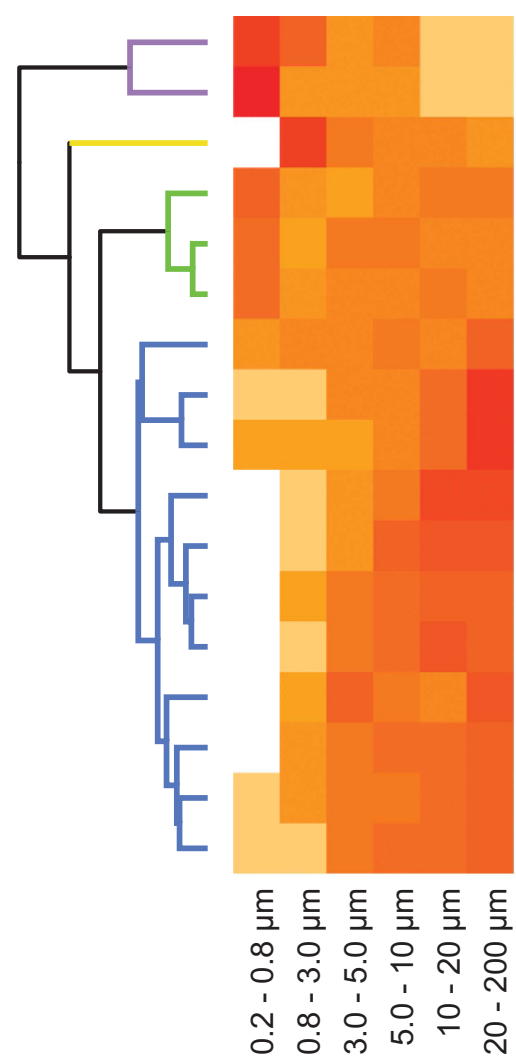

SAR116, Alphaproteobacteria

SAR11, Alphaproteobacteria

Synechococcus, Cyanobacteria

Actinobacteria

Deferribacteres

Oceanospirillales, Gammaproteobacteria

Rhodobacterales, Alphaproteobacteria

Alteromonadales, Gammaproteobacteria

Cytophagia, Bacteroidetes

Vibrionales, Gammaproteobacteria

Sphingobacteriia, Bacteroidetes

Firmicutes

Planctomycetes

Verrucomicrobia

Rhizobiales, Alphaproteobacteria

Deltaproteobacteria

Flavobacteria, Bacteroidetes

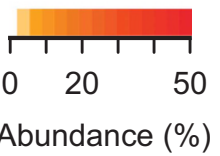

Figure 8 Heatmap representing the relative abundances of individual taxonomic groups among size-fractions. The taxonomic groups were clustered hierarchically by the UPGMA method. A total of four categories were differentiated: (a) taxonomic groups enriched in the small size-fractions; (b) taxonomic groups enriched in increasing size-fractions, but depleted or absent in the smallest one (0.2-0.8 $\mu \mathrm{m})$; (c) taxonomic groups that do not present enrichment in relation with the size-fraction; and (d) taxonomic groups enriched in increasing size-fractions. The data presented are the average of the 8 months.

that may occupy a niche in association with larger bacterioplankton and phytoplankton (Allen et al., 2012). The relatively large presence of SAR11 in larger particles occurred in 2 months in particular, suggesting that this particle-attachment could appear under specific environmental conditions only. This would be consistent with the extensively described microdiversity within the SAR11 clade (GarcíaMartínez and Rodríguez-Valera, 2000; Brown and Fuhrman, 2005).

Other relevant bacterial groups that presented the same pattern as SAR11 (that is, were enriched mainly in the $0.2-0.8 \mu \mathrm{m}$ fraction: category 'a', Figure 8) were the 'SAR116' ( $>1 \%$ of the $0.2 \mu \mathrm{m}$ community and $<1 \%$ in the largest size-fractions). It is interesting to point out that in a previous $16 \mathrm{~S}$ rDNA pyrotag sequencing study of the composition of sorted highnucleic acid containing (HNA) and low-nucleic acid containing (LNA) bacteria from Blanes Bay done a few years before the current study, SAR11 were enriched in the LNA cell fraction while SAR116 were enriched in the HNA fraction (Vila-Costa et al., 2012). This same pattern was observed also for the Acidobacteria, the Betaproteobacteria and for the Gammaproteobacteria (enriched in the LNA in the study by Vila-Costa et al., but present in the higher size-fractions in our study).
Other groups enriched in the HNA cells in that study (such as the Rhodobacterales and the Bacteroidetes) presented higher contributions to community structure in the larger sizes in our current work (see below). We take these contrasting observations as evidence that association to particles (and thus, to large sizefractions) is not directly a size (and genome content) -related feature of the different organisms, but goes beyond that feature in what has been considered a 'lifestyle', that is known to present a phylogenetically defined signal (that is, Salazar et al., 2015).

Cyanobacteria of genus Synechococcus sp. were also enriched in small size-fractions with relative abundance maxima in the $0.8-3.0 \mu \mathrm{m}$ size-fraction (Figure 8: category 'b'; $50 \%$ of the community) and almost non-existent in the smallest size-fraction $(0.2-0.8 \mu \mathrm{m},<2 \%$ of the community). The average size of Synechococcus sp. is $\sim 1 \mu \mathrm{m}$ (for example, Morel et al., 1993), which is larger than that of most FL bacteria, so they are large enough to be retained by the $0.8 \mu \mathrm{m}$ filter and not contribute to the smaller fraction. In fact, the absence of Synechoccocus sp. from the $0.2-0.8 \mu \mathrm{m}$ fraction and the relatively low contribution to the community in the size-fractions $>3 \mu \mathrm{m}$ indicate that the filtration system used was successful and bias-free. 
If Synechoccocus had been found in the $<0.8 \mu \mathrm{m}$ fraction or abundantly in the $>3 \mu \mathrm{m}$, it would have raised concerns on the quality of the filtration. Their absence supports our size-fractionation protocol.

In contrast with the patterns observed in SAR11 and Synechococcus sp., some taxonomic groups were enriched in the largest size-fractions (Figure 8: category 'd'). Generally the taxonomic groups in category ' $d$ ' had been found in the ATT bacterial fraction in previous studies in the Mediterranean. Planctomycetes together with Bacteroidetes and Alpha- and Proteobacteria were found enriched in particles in the Adriatic Sea (BižicIonescu et al., 2015); In the NW Mediterranean, Bacteroidetes was the most important group in the ATT fraction, although as in our study, also Firmicutes or Verrucomicrobia were abundant phyla (Crespo et al., 2013). In other contrasting environments, such as at $6000 \mathrm{~m}$ in the Puerto Rico Trench (Eloe et al., 2011) or in the Black Sea suboxic zone (Fuchsman et al., 2011) other groups were found in the ATT fraction, but Planctomycetes was always found enriched in particles. The phylum 'Planctomycetes' has been described as able to attach to surfaces (Bauld and Staley, 1976) such as macroalgae (Bengtsson and Øvreås, 2010; Lage and Bondoso, 2011), invertebrates (Fuerst et al., 1997) or macroscopic detrital aggregates (Delong et al., 1993; Crump et al., 1999), where they contribute to biopolymer degradation (Woebken et al., 2007). They were $>3 \%$ of the communities of sizes $>3 \mu \mathrm{m}$, but $\sim 1 \%$ in the smallest size-fractions (Figure 3).

Phylum 'Bacteroidetes' is here represented by classes Flavobacteria, Cytophagia and Sphingobacteriia, and all of them were enriched in the large sizefractions. They were $\sim 20-30 \%$ of the communities of sizes $>3 \mu \mathrm{m}$, but $<10 \%$ in the smallest sizefractions. Phylum Bacteroidetes has been known to contain heterotrophic bacteria with capacity for adhesion to particles (Williams et al., 2012) and production of extracellular enzymes with degradative capabilities (Kirchman, 2002), which allow them to have an important role during algal blooms (Buchan et al., 2014). Moreover some bacteroidetes have the capacity to survive as FL cells in situations of low levels of nutrients and the presence of light, thanks to the proteorhodopsin gene (González et al., 2008). This might explain their presence also in the smallest size-fraction.

The phylum 'Verrucomicrobia' was also enriched when increasing the size-fraction. This group has been observed in marine snow (Rath et al., 1998), where they are very efficient biopolymer degraders (Martinez-Garcia et al., 2012), and they have also been observed in association with nanoeukaryotic cells (Petroni et al., 2000). The association of Verrucomicrobia and eukaryonts is that close that it has even been speculated that Verrucomicrobia was the origin of the eukaryotic flagella ( $\mathrm{Li}$ and $\mathrm{Wu}, 2005)$. The possible association with nanoeucaryotes would explain the observed elevated values of Verrucomicobia in the $3.0-5.0 \mu \mathrm{m}$ sizefraction $(\sim 2 \%)$.

Finally, some groups did not present a gradient of enrichment when increasing or decreasing the sizefraction (Figure 8: category 'c'). 'Actinobacteria' were enriched in the smallest size-fraction but presented also enrichment in the largest size-fractions. As SAR11, they have been described as small FL cells with streamlined genome and with rhodopsins that allows a photoheterotrophic metabolism (Ghai et al., 2013). And as in SAR11, we can interpret the enrichment in large size-fractions as caused by the presence of different ecotypes. These ecotypes might be expressing light-capturing proteorhodopsin in the particle microenvironment, as has already been described in a river plume (Satinsky et al., 2014).

Following the Sieburth et al. (1978) nomenclature, the size spectra sampled by our multiple sizefractionation comprises from the pico- $(0.2 \mu \mathrm{m})$ to the microplankton sizes $(200 \mu \mathrm{m})$, where we observed a saturation of the species-accumulation curve. This defines the border between the classic 'microbial environment', spatially structured by pico/nanostructures, and a 'non-microbial environment', characterized by larger structures. This information might be useful in the design of multiscale studies focusing on the holistic description of the community (Pinel-Alloul and Ghadouani, 2007). Therefore, the knowledge of the dynamics at small scales and their implications for larger scales would allow us to improve our understanding of global ocean biogeochemistry (Azam and Malfatti, 2007).

Concluding, we show that the size of the particle is crucial for determining prokaryotic community structure, and the use of various size-fractions reveals a more comprehensive view of the pelagic microorganisms in the plankton. Moreover, and in the same way as the dichotomy of particulate organic matter vs dissolved organic matter is more accurately regarded as a continuum of sizes (Azam et al., 1993; Verdugo et al., 2004), the dichotomy of FL vs ATT bacteria should be better regarded as gradients of enrichment in larger or smaller size-fractions. This approach provides a more integrated perspective of the relations between the ecology of microbes and the chemical substrates presents in the ocean.

\section{Conflict of Interest}

The authors declare no conflict of interest.

\section{Acknowledgements}

We thank the people involved in operating the BBMO, especially Clara Cardelús for facilitating sampling, and Carolina Antequera for laboratory procedures. We also thank the Bioinformatics Service of the Institut de Ciències del Mar, in particular Vanessa Balagué and Ramiro Logares-Haurie for bioinformatics assistance and Pablo Sánchez for computing support. We appreciate the 
valuable comments of the anonymous reviewers. This research was funded by projects STORM (CTM200909352), ADEPT (CTM2011-23458), DOREMI (CTM201234294), REMEI (CTM2015-70340-R) and ANIMA (CTM2015-65720-R) funded by the former Ministry of Science and Innovation and the Ministry of Economy and Competitiveness. MM was supported by a CSIC JAEPredoc Grant and by the Ministry of Labor, Employment and Social Security. EB was supported by an FPI predoctoral fellowship from the Spanish Ministery of Economy and Competitiveness.

\section{References}

Acinas SG, Antón J, Rodríguez-Valera F. (1999). Diversity of free-living and attached bacteria in offshore western Mediterranean waters as depicted by analysis of genes encoding 16S rRNA. Appl Environ Microb 65: $514-522$.

Alldredge AL, Cole JJ, Caron DA. (1986). Production of heterotrophic bacteria inhabiting macroscopic surface organic aggregates (marine snow) from surface waters. Limnol Oceanogr 31: 68-78.

Alldredge AL, Cohen Y. (1987). Can microscale chemical patches persist in the sea? Microelectrode study of marine snow, fecal pellets. Science 235: 689-691.

Allen ZL, Allen EE, Badger JH, McCrow JP, Paulsen IT, Elbourne LDH et al. (2012). Influence of nutrients and currents on the genomic composition of microbes across an upwelling mosaic. ISME J 6: 1403-1414.

Almeda R, Calbet A, Alcaraz M, Saiz E, Trepat I, Arin L et al. (2011). Trophic role and carbon budget of metazoan microplankton in northwest Mediterranean coastal waters. Limnol Oceanogr 56: 415-430.

Azam F, Smith DC, Steward GF, Hagström A. (1993). Bacteria-organic matter coupling and its significance for oceanic carbon cycling. Microb Ecol 28: 167-179.

Azam F. (1998). Microbial control of oceanic carbon flux: the plot thickens. Science 280: 694-696.

Azam F, Malfatti F. (2007). Microbial structuring of marine ecosystems. Nat Rev Microbiol 5: 782-791.

Bauld J, Staley JT. (1976). Planctomyces maris sp. nov.: a marine isolate of the Planctomyces-Blastocaulis group of budding bacteria. J Gen Microbiol 97: 45-55.

Baumann P, Baumann L, Bang S, Woolkalis MJ. (1980). Reevaluation of the taxonomy of Vibrio, Beneckea, and Photobacterium: abolition of the genus Beneckea. Current Microbiol 4: 127-132.

Bengtsson MM, Øvreås L. (2010). Planctomycetes dominate biofilms on surfaces of the kelp Laminaria hyperborea. BMC Microbiol 10: 261.

Bickel SL, Tang KW, Grossart HP. (2014). Structure and function of zooplankton-associated bacterial communities in a temperate estuary change more with time than with zooplankton species. Aquat Microb Ecol 72: 1-15.

Bižic-Ionescu M, Zeder M, Ionescu D, Orlic S, Fuchs BM, Grossart HP et al. (2015). Comparison of bacterial communities on limnic versus coastal marine particles reveals profound differences in colonization. Environ Microbiol 17: 3500-3514.

Brown MV, Fuhrman JA. (2005). Marine bacterial microdiversity as revealed by internal transcribed spacer analysis. Aquat Microb Ecol 41: 15-23.
Buchan A, LeCleir GR, Gulvik CA, González JM. (2014). Master recyclers: features and functions of bacteria associated with phytoplankton blooms. Nat Rev Microbiol 12: 686-698.

Calbet A, Garrido S, Saiz E, Alcaraz M. (2001). Annual zooplankton succession in coastal NW Mediterranean waters: the importance of the smaller size fractions. J Plankton Res 23: 319-331.

Caporaso JG, Kuczynski J, Stombaugh J, Bittinger K, Bushman FD, Costello EK et al. (2010). QIIME allows analysis of high-throughput community sequencing data. Nat Methods 7: 335-336.

Crespo BG, Pommier T, Fernández-Gómez B, Pedrós-Alió C. (2013). Taxonomic composition of the particleattached and free-living bacterial assemblages in the Northwest Mediterranean Sea analyzed by pyrosequencing of the $16 \mathrm{~S}$ rRNA. MicrobiologyOpen 2: 541-552.

Crump BC, Armbrust EV, Baross JA. (1999). Phylogenetic analysis of particle-attached and free-living bacterial communities in the Columbia River, its estuary, and the adjacent coastal ocean. Appl Environ Microb 65: 3192-3204.

Dang H, Lovell CR. (2002). Seasonal dynamics of particleassociated and free-living marine Proteobacteria in a salt marsh tidal creek as determined using fluorescence in situ hybridization. Environ Microb 4: 287-295.

Delong EF, Franks DG, Alldredge AL. (1993). Phylogenetic diversity of aggregate-attached vs free-living marine bacterial assemblages. Limnol Oceanogr 38: 924-934.

Dufrene M, Legendre P. (1997). Species assamblages and indicator species: the need for a flexible asymetrical approach. Ecol Monograph 67: 345-366.

Eloe EA, Shulse CN, Fadrosh DW, Williamson SJ, Allen EE, Bartlett DH. (2011). Compositional differences in particle-associated and free-living microbial assemblages from an extreme deep-ocean environment. Environ Microbiol Rep 3: 449-458.

Fenchel T. (2001). Eppur si muove: many water column bacteria are motile. Aquat Microb Ecol 24: 197-201.

Fuchsman CA, Kirkpatrick JB, Brazelton WJ, Murray JW, Staley JT. (2011). Metabolic strategies of free-living and aggregate-associated bacterial communities inferred from biologic and chemical profiles in the Black Sea suboxic zone. FEMS Microbiol Ecol 78: 586-603.

Fuerst J, Gwilliam HG, Lindsay M, Lichanska A, Belcher C, Vickers JE et al. (1997). Isolation and molecular identification of planctomycete bacteria from postlarvae of the giant tiger prawn, Penaeus monodon. Appl Environ Microb 63: 254-262.

Ganesh S, Parris DJ, DeLong EF, Stewart FJ. (2014). Metagenomic analysis of size-fractionated picoplankton in a marine oxygen minimum zone. ISME J 8: 187-211.

García-Martínez J, Rodríguez-Valera F. (2000). Microdiversity of uncultured marine prokaryotes: The SAR11 cluster and the marine Archaea of Group I. Molecular Ecol 9: 935-948.

Gasol JM, Massana R, Simó R, Marrasé C, Acinas SG, Pedrós-Alió C et al. (2012). Blanes Bay. In: O'Brien TD, Li WK, Morán XAG (eds), ICES Phytoplankton and Microbial Plankton Status Report 2009/2010. ICES Cooperative Research Report no. 313. ICES: Copenhagen, Denmark. Available at: http://www.st.nmfs.noaa. gov/copepod/status-reports/crr313-wgpme_large.pdf. 
Ghai R, Mizuno CM, Picazo A, Camacho A, RodriguezValera F. (2013). Metagenomics uncovers a new group of low GC and ultra-small marine Actinobacteria. Sci Rep 3: 1-8.

Ghiglione J, Mevel G, Pujo-Pay M, Mousseau L, Lebaron P, Goutx M. (2007). Diel and seasonal variations in abundance, activity, and community structure of particle-attached and free-living bacteria in NW Mediterranean Sea. Microb Ecol 54: 217-231.

Giovannoni SJ, Tripp HJ, Givan S, Podar M, Vergin KL, Baptista D et al. (2005). Genome streamlining in a cosmopolitan oceanic bacterium. Science 309: 1214.

González JM, Fernández-Gómez B, Fernàndez-Guerra A, Gómez-Consarnau L, Sánchez O, Coll-Lladó M et al. (2008). Genome analysis of the proteorhodopsincontaining marine bacterium Polaribacter sp. MED152 (Flavobacteria). Proc Natl Acad Sci USA 105: 8724-8729.

Grossart HP, Riemann L, Azam F. (2001). Bacterial motility in the sea and its ecological implications. Aquat Microb Ecol 25: 247-258.

Grossart HP, Tang KW, Kiørboe T, Ploug H. (2007). Comparison of cell-specific activity between freeliving and attached bacteria using isolates and natural assemblages. FEMS Microbiol Ecol 266: 194-200.

Grossart HP. (2010a). Ecological consequences of bacterioplankton lifestyles: changes in concepts are needed. Environ Microbiol Rep 2: 706-714.

Grossart HP, Dziallas C, Leunerta F, Tang KW. (2010b). Bacteria dispersal by hitchhiking on zooplankton. Proc Natl Acad Sci USA 107: 11959-11964.

Gutiérrez-Rodríguez A, Latasa M, Scharek R, Massana R, Vila G, Gasol JM. (2011). Growth and grazing rate dynamics of major phytoplankton groups in an oligotrophic coastal site. Estuar Coast Shelf Sci 95: 77-87.

Haas BJ, Gevers D, Earl AM, Feldgarden M, Ward DV, Giannoukos G et al. (2011). Chimeric 16S rRNA sequence formation and detection in Sanger and 454-pyrosequenced PCR amplicons. Genome Res 21: 494-504.

Hollibaugh JT, Wong PS, Murrell MC. (2000). Similarity of particle-associated and free-living bacterial communities in northern San Francisco Bay, California. Aquat Microb Ecol 21: 103-104.

Karl DM, Knauer GA, Martin JH, Ward BB. (1984) Bacterial chemolithotrophy in the ocean is associated with sinking particles. Nature 309: 54-56.

Karner M, Herndl GJ. (1992). Extracellular enzymatic activity and secondary production in free-living and marine-snow-associated bacteria. Mar Biol 113: 341-347.

Kellogg C, Deming J. (2009). Comparison of free-living, suspended particle, and aggregate-associated bacterial and archaeal communities in the Laptev Sea. Aquat Microb Ecol 57: 1-18.

Kirchman D. (2002). The ecology of Cytophaga-Flavobacteria in aquatic environments. FEMS Microbiol Ecol 39: 91-100.

Kirchman D, Mitchell R. (1982). Contribution of particlebound bacteria to total microheterotrophic activity in five ponds and two marshes. Appl Environ Microbiol 43: 200-209.

Lage OM, Bondoso J. (2011). Planctomycetes diversity associated with macroalgae. FEMS Microbiol Ecol 78: $366-375$
Lapoussière A, Michel C, Starr M, Gosselin M, Poulin M. (2011). Role of free-living and particle-attached bacteria in the recycling and export of organic material in the Hudson Bay System. J Mar Syst 88: 434-445.

Levins R. (1968). Evolution in Changing Environments. Princeton University Press: Princeton, NJ, USA.

Li JY, Wu CF. (2005). New symbiotic hypothesis on the origin of eukaryotic flagella. Naturwissenschaften 92: 305-309.

Long RA, Azam F. (2001). Microscale patchiness of bacterioplankton assemblage richness in seawater. Aquat Microb Ecol 26: 103-113.

Malfatti F, Azam F. (2009). Atomic force microscopy reveals microscale networks and possible symbioses among pelagic marine bacteria. Aquat Microb Ecol 58: $1-14$.

Martinez-Garcia M, Brazel DM, Swan BK, Arnosti C, Chain PSG, Reitenga KG et al. (2012). Capturing single cell genomes of active polysaccharide degraders: an unexpected contribution of Verrucomicrobia. PLOS One 7: e35314.

Massana R, Murray AE, Preston CM, DeLong E. (1997). Vertical distribution and phylogenetic characterization of marine planktonic archaea in the Santa Barbara Channel. Appl Environ Microbiol 63: 50-56.

Milici M, Tomasch J, Wos-Oxley M, Wang H, Jáuregui R, Camanirha-Silva A et al. (2016). Low diversity of planktonic bacteria in the tropical ocean. Sci Rep 6: 19054.

Mitchell JG, Pearson L, Dillon S, Kantalis K. (1995). Natural assemblages of marine bacteria exhibiting high-speed motility and large accelerations. Appl Environ Microbiol 61: 4436-4440.

Moeseneder MM, Winter C, Herndl GJ. (2001). Horizontal and vertical complexity of attached and free-living bacteria of the eastern Mediterranean Sea, determined by $16 \mathrm{~S}$ rDNA and $16 \mathrm{~S}$ rRNA fingerprints. Limnol Oceanogr 46: 95-107.

Morel A, Ahn YH, Partensky F, Vaulot D, Claustre H. (1993). Prochlorococcus and Synechococcus: a comparative study of their optical properties in relation to their size and pigmentation. J Mar Res 51: 617-649.

Ortega-Retuerta E, Joux F, Jeffrey WH, Ghiglione JF. (2013). Spatial variability of particle-attached and free-living bacterial diversity in surface waters from the Mackenzie River to the Beaufort Sea (Canadian Arctic). Biogeosciences 10: 2747-2759.

Petroni G, Spring S, Schleifer KH, Verni F, Rosati G. (2000). Defensive extrusive ectosymbionts of Euplotidium (Ciliophora) that contain microtubule-like structures are bacteria related to Verrucomicrobia. Proc Natl Acad Sci USA 97: 1813-1817.

Pinel-Alloul B, Ghadouani A. (2007). Spatial heterogeneity of planktonic microorganisms in aquatic systems. In: Franklin R, Mills A (eds). The Spatial Distribution of Microbes in the Environment. Springer Press: Dordrecht, pp 210-310.

Pinhassi J, Sala MM, Havskum H, Peters F, Guadayol Ò, Malits A et al. (2004). Changes in bacterioplankton composition under different phytoplankton regimes. Appl Environ Microb 70: 6753-6766.

Rath J, Wu KY, Herndl GJ, DeLong EF. (1998). High phylogenetic diversity in a marine-snow-associated bacterial assemblage. Aquat Microb Ecol 14: 261-269.

Sala MM, Balagué V, Pedrós-Alió C, Massana R, Felipe J, Arin L et al. (2005). Phylogenetic and functional 
diversity of bacterioplankton during Alexandrium spp. blooms. FEMS Microbiol Ecol 54: 257-267.

Salazar G, Cornejo-Castillo FM, Borrull E, Díez C, Lara E, Vaqué D et al. (2015). Particle-association lifestyle is a phylogenetically conserved trait in bathypelagic prokaryotes. Mol ECol 24: 5692-5706.

Satinsky BM, Crump BC, Smith CB, Sharma S, Zielinski BL, Doherty $\mathrm{M}$ et al. (2014). Microspatial gene expression patterns in the Amazon River Plume. Proc Natl Acad Sci USA 111: 11085-11090.

Schapira M, McQuaid CD, Froneman PW. (2012). Metabolism of free-living and particle-associated prokaryotes: Consequences for carbon flux around a Southern Ocean archipelago. J Marine Syst 90: 58-66.

Schink B, Pfennig N. (1982). Propionigenium modestum gen. nov. sp. nov. a new strictly anaerobic, nonsporing bacterium growing on succinate. Archiv Microbiol 133: 209-216.

Schlesner H, Rensmann C, Tindall BJ, Gade D, Rabus R et al. (2004). Taxonomic heterogeneity within the Planctomycetales as derived by DNA-DNA hybridization, description of Rhodopirellula baltica gen. nov., sp. nov., transfer of Perillula marina to the genus Blastopirellula gen. nov. as Blastopirellula marina comb. nov. and emended description of the genus Pirellula. Int J Syst Evol Microbiol 54: 1567-1580.

Schloss PD, Westcott SL, Ryabin T, Hall JR, Hartmann M, Hollister EB et al. (2009). Introducing mothur: opensource, platform-independent, community-supported software for describing and comparing microbial communities. Appl Environ Microbiol 75: 7537-7541.

Seymour JR, Mitchell JG, Seuront L. (2004). Microscale heterogeneity in the activity of coastal bacterioplankton communities. Aquat Microb Ecol 35: 1-16.

Sieburth JM, Smetacek V, Lenz J. (1978). Pelagic ecosystem structure: heterotrophic compartments of the plankton and their relationship to plankton size fractions. Limnol Oceanogr 23: 1256-1263.

Simon M, Grossart HP, Schweitzer B, Ploug H. (2002). Microbial ecology of organic aggregates in aquatic ecosystems. Aquat Microb Ecol 28: 175-211.

Sison-Mangus MP, Jiang S, Kudela RM, Mehic S. (2016). Phytoplankton-associated bacterial community composition and succession during toxic diatom bloom and non-bloom events. Front Microbiol 7: 1433.
Smith D, Simon M, Alldredge A, Azam F. (1992). Intense hydrological enzyme activity on marine aggregates and implications for rapid particle dissolution. Nature 359: 139-142.

Smith MW, Allen LZ, Allen AE, Herfort L, Simon HM. (2013). Contrasting genomic properties of free-living and particle-attached microbial assemblages within a coastal ecosystem. Front Microbiol 4: 120.

Suzuki M, Nakagawa Y, Harayama S, Yamamoto S. (2001). Phylogenetic analysis and taxonomic study of marine Cytophaga-like bacteria: Proposal for Tenacibaculum gen. nov. with Tenacibaculum maritimum comb. nov. and Tenacibaculum ovolyticum comb. nov., and description of Tenacibaculum mesophilum sp. nov. and Tenacibaculum amylolyticum sp. nov. Int J Syst Evol Microbiol 51: 1639-1652.

Tuomisto H. (2010). A diversity of beta diversities: Straightening up a concept gone awry. Part 1. Defining beta diversity as a function of alpha and gamma diversity. Ecography 33: 2-22.

Verdugo P, Alldredge AL, Azam F, Kirchman DL, Uta Passow, Santschi PH. (2004). The oceanic gel phase: a bridge in the DOM-POM continuum. Mar Chem 92: 67-85.

Vila-Costa M, Gasol JM, Sharma S, Moran MA. (2012). Community analysis of high- and low-nucleic acidcontaining bacteria in NW Mediterranean coastal waters using $16 \mathrm{~S}$ rDNA pyrosequencing. Environ Microbiol 14: 1390-1402.

Wilkins D, van Sebille E, Rintoul SR, Lauro FM, Cavicchioli R. (2013). Advection shapes Southern Ocean microbial assemblages independent of distance and environment effects. Nat Commun 4: 2457.

Williams TJ, Long E, Evans F, Demaere MZ, Lauro FM, Raftery MJ et al. (2012). A metaproteomic assessment of winter and summer bacterioplankton from Antarctic Peninsula coastal surface waters. ISME J 6: 1883-1900.

Woebken D, Teeling H, Wecker P, Dumitriu A, Kostadinov I, Delong EF et al. (2007). Fosmids of novel marine Planctomycetes from the Namibian and Oregon coast upwelling systems and their cross-comparison with planctomycete genomes. ISME J 1: 419-435.

Zhang R, Liu B, Lau SCK, Ki JS, Qian PY. (2007). Particleattached and free-living bacterial communities in a contrasting marine environment: Victoria Harbor, Hong Kong. FEMS Microbiol Ecol 61: 496-508.

Supplementary Information accompanies this paper on The ISME Journal website (http://www.nature.com/ismej) 